\title{
Peptides in low molecular weight fraction of serum associated with hepatocellular carcinoma
}

\author{
Yanming $\mathrm{An}^{\mathrm{a}}$, Slavka Bekesova ${ }^{\mathrm{a}}$, Nathan Edwards ${ }^{\mathrm{b}}$ and Radoslav Goldman ${ }^{\mathrm{a}, \mathrm{b}, *}$ \\ ${ }^{a}$ Georgetown University, Department of Oncology, Lombardi Comprehensive Cancer Center, Washington, DC, \\ USA \\ ${ }^{\mathrm{b}}$ Georgetown University, Department of Biochemistry and Molecular \& Cellular Biology, Washington, DC, USA
}

\begin{abstract}
The incidence of hepatocellular carcinoma (HCC) in the United States is increasing and the increase is projected to continue for several decades. The overall survival of HCC patients is poor and treatments are not effective in part because most of the diagnoses come at a late stage. The development of new markers for detection of HCC would significantly improve patient prognosis. This paper describes identification of candidate markers previously reported in our serologic study of an Egyptian population by quantitative comparison of matrix assisted laser desorption ionization time of flight (MALDI-TOF) mass spectra. To identify these marker candidates, we performed LC-MS/MS sequencing that identified nine native peptides associated with $\mathrm{HCC}$, including two reported previously. Four truncations of $\mathrm{N}$ terminus of complement $\mathrm{C} 3 \mathrm{f}$ and a fibrinopeptide increased in control sera; two complement $\mathrm{C} 4 \alpha$ peptides, a zyxin peptide, and a coagulation factor XIII peptide increased in cancer patient sera. We have also identified increased biliverdin diglucuronide in the sera of cancer patients. These peptides could potentially serve as markers of HCC following additional validation studies; however, association of similar peptides with other diseases and cancers dictates a very cautious approach.
\end{abstract}

Keywords: Hepatocellular carcinoma, mass spectrometry, serum, complement, biliverdin diglucuronide

\section{Introduction}

Hepatocellular carcinoma (HCC) is a highly fatal cancer that affects annually approximately half a million people worldwide [1,2]. Liver cancer ranks fifth in frequency of cancers in the world. Since the mid1980s, the incidence of HCC in the United States has been rising and this increase is predicted to continue in the next few decades primarily due to hepatitis $\mathrm{C}$ viral (HCV) infection [2-5]. The overall survival rate of $\mathrm{HCC}$ patients is poor which is in part related to the lack of reliable tools for early diagnosis. A diagnosis of HCC is often made at a late stage when the disease is too advanced for an effective treatment. Surveillance of patients at high risk for developing HCC is

* Corresponding author: Radoslav Goldman, Department of Oncology, Georgetown University Medical Center, 3970 Reservoir Rd NW, LCCC Room S183, Washington, DC 20057, USA. Tel.: +1 202 687 9868; Fax: +1 202687 1988; E-mail: rg26@georgetown.edu. an important strategy that can potentially decrease the cancer-related mortality.

Chronic hepatitis $\mathrm{C}$ viral infection with subsequent liver cirrhosis is the major risk factor for development of HCC [2,6,7]. Patients with cirrhosis are recommended to undergo routine surveillance. Diagnosis is most often based on radiological imaging. Abdominal ultrasound is the most common imaging modality used in the surveillance of HCC, but it is operator dependent and limited in its ability to differentiate HCC from such non-neoplastic lesions as regenerative nodules [2,8]. The only serologic marker for HCC surveillance is alpha fetoprotein (AFP). AFP has reported sensitivity of 39 to $65 \%$, specificity of 76 to $94 \%$, and positive predictive values of $9 \%$ to $50 \%$ [2,9]. This is not sufficient for an efficient detection of HCC. New biomarkers for early detection and prevention of $\mathrm{HCC}$ are needed and a search is under way in several laboratories [10-13]. The management of the disease is predicted to benefit from identification of appropriate serologic markers 
that would assist with the optimization of therapeutic decisions.

It was shown that the presence of tumors is associated with changes in the composition of native peptides in serum [14]. Liver is a major source of circulating proteins and $\mathrm{HCC}$ is expected to induce significant perturbations. Proteases and peptidases are reportedly deregulated in HCC [15-18] and it is reasonable to expect that cancer-specific peptides and fragments of proteins will be found in the low molecular weight fraction of serum [19-21].

Our laboratory has developed a denaturing ultrafiltration method for enrichement of the LMW serum proteins and peptides for MALDI-TOF mass spectrometric analysis $[19,20]$. The method has allowed a fast comparison of hundreds of patient samples which is expected to decrease the gap between marker discovery and clinical validation [22]. In previous articles, we reported consistent differences associated with HCC in a large sample of patients from an Egyptian population ( 73 HCC cases, 72 cancer-free controls, and 52 chronic liver disease controls) $[19,21]$. Here we describe mass spectrometric identification of nine of the differentially abundant peptide peaks which will further facilitate examination of their association with HCC.

\section{Experimental procedures}

\subsection{Materials}

AmiconUltra-4 Centrifugal Filter Devices with 30 $\mathrm{kDa}$ cut-off were purchased from Millipore (Bedford, MA, USA). Sep-Pak Vac RC C18 Cartridges were bought from Waters Corporation (Milford, MA). BCA protein assay was purchased from Pierce Biotechnology (Rockford, IL, USA). $\alpha$-cyano-4-hydroxycinaminic acid (CHCA) was purchased from Bruker Daltonics (Billerica, MA, USA). Opti-TOF 384 well MALDI plate and mass calibration standards were purchased from Applied Biosystems (Framingham, MA). Other chemicals and solvents were purchased from SigmaAldrich (St. Louis, MO, USA); solvents were of HPLC grade.

\section{Blood sample collection and preparation}

Serum samples of HCC cases and controls with(out) chronic liver disease were obtained in collaboration with the National Cancer Institute of Cairo University,
Egypt from 2000 to 2002 as described previously [19, 21]. Blood samples were collected by a trained phlebotomist around 10 am and processed within a few hours according to a standard protocol. Aliquots of sera were frozen at $-80^{\circ} \mathrm{C}$ immediately after processing until analysis; all mass spectrometric measurements were performed on twice-thawed sera. For sequencing of peptides, $0.5 \mathrm{ml}$ of serum was diluted in $2.5 \mathrm{ml} 8 \mathrm{M}$ guanidine hydrochloride and ultrafiltered at 3,000 x g for 90 minutes at $4^{\circ} \mathrm{C}$ using $30-\mathrm{kDa}$ AmiconUltra membrane (Millipore). The ultrafiltrate was desalted on a Sep-Pak C18 cartridge (Waters) according to the manufacture's protocol and dried in a centrifugal vacuum evaporator.

\section{Fractionation of proteins}

The dried ultrafiltrate was resuspended in $20 \mu \mathrm{L}$ $0.1 \%$ TFA/water and separated on Chromolith Performance RP-18 Column $(100 \times 4.6 \mathrm{~mm})($ EMD Chemicals, NJ) at room temperature. A flow $(1 \mathrm{~mL} / \mathrm{min})$ of solvent gradient (5\% of solvent B for $2 \mathrm{~min}, 5-40 \%$ of solvent B for $23 \mathrm{~min}, 40-95 \%$ of solvent B for $2 \mathrm{~min}$, $95 \%$ of solvent B in $3 \mathrm{~min}, 95-5 \%$ solvent $\mathrm{B}$ in $1 \mathrm{~min}$, and $5 \%$ of solvent B for $10 \mathrm{~min}$; Solvent A: $100 \%$ water / $0.1 \%$ TFA, Solvent B: $100 \%$ acetonitrile $/ 0.1 \%$ TFA) was used for separation using an Agilent 1100 HPLC system with fractions collected every 30 seconds from 0 to 30 minutes. The fractions were dried in a centrifugal vacuum evaporator. Each fraction was analyzed using MALDI-TOF or ESI-QqTOF mass spectrometers as described below.

\section{MALDI-TOF/TOF analysis of peptides}

A 4800 MALDI TOF/TOF ${ }^{\text {TM }}$ Analyzer (Applied Biosystems, CA) was used for the peptide analysis. Each dried fraction was resuspended in $1 \mu \mathrm{L}$ matrix (a-Cyano-4-hydroxycinnamic acid, $3.3 \mathrm{mg} / \mathrm{mL}$ in $50 \%$ Acetonitrile/ $50 \%$ water/ $0.1 \%$ TFA) and spotted on a MALDI plate for analysis in positive ion mode in 800$5,500 \mathrm{~m} / \mathrm{z}$ range. In both reflector and $\mathrm{MS} / \mathrm{MS}$ mode, laser repetition rate was $200 \mathrm{~Hz}$ and the instrument default calibration was used. Precursor list for MS/MS was generated for all fractions and the top 15 ions were selected for MS/MS analysis. The ions of interest as the biomarker candidates were selected for MS/MS analysis if they were not in the precursor list. In MSMS mode, $2 \mathrm{kV}$ collision energy (with CID gas on) was used to fragment the peptides. 
Table 1

Sequences of identified peptides and a metabolite associated with HCC [19,21]

\begin{tabular}{|c|c|c|c|c|c|}
\hline Monoisotopic mass & Sequence & Protein source & Increased in & MASCOT score & Expect \\
\hline 1863.98 & SSKITHRIHWESASLL & Complement C3 & Control & 76 & 0.0023 \\
\hline 1776.95 & SKITHRIHWESASLL & Complement $\mathrm{C} 3$ & Control & 83 & 0.00027 \\
\hline 1689.92 & KITHRIHWESASLL & Complement $\mathrm{C} 3$ & Control & 76 & 0.0012 \\
\hline 1561.83 & ITHRIHWESASLL & Complement C3 & Control & 78 & 0.00072 \\
\hline 1738.91 & NGFKSHALQLNNRQI & Complement C4A & $\mathrm{HCC}$ & 115 & $3.2 \mathrm{e}-7$ \\
\hline 2377.19 & DDPDAPLQPVTPLQLFEGRRN & Complement $\mathrm{C} 4 \mathrm{~A}$ & $\mathrm{HCC}$ & 106 & $4 e-6$ \\
\hline 2530.26 & VPPNNSNAAEDDLPTVELQGVVPR & Coagulation factor XIII A & $\mathrm{HCC}$ & 135 & $5.1 \mathrm{e}-9$ \\
\hline 1379.57 & ADSGEGDFLAEGGGV & Fibrinogen alpha & Control & 63 & 0.0086 \\
\hline 2303.20 & HVQPQPQPKPQVQLHVQSQT & Zyxin & $\mathrm{HCC}$ & 122 & $3 e-8$ \\
\hline 933.31 & $\mathrm{C}_{45} \mathrm{H}_{50} \mathrm{~N}_{4} \mathrm{O}_{18}$ & Biliverdin diglucuronide & $\mathrm{HCC}$ & N/A & N/A \\
\hline
\end{tabular}

\section{NanoLC-QqTOF analysis of peptides}

Each dried fraction was redissolved in $5 \mu \mathrm{L} 0.1 \%$ formic acid/water and separated on a Nano Acquity Ultra Performance LC system (Waters). The sample was desalted on a Symmetry C18 $180 \mu$ m i.d. $\times 20 \mathrm{~mm}$ pre-column (Waters) and then injected onto a BEH130 C18 $100 \mu$ m i.d. $\times 100 \mathrm{~mm}$ analytical column (Waters). The peptides were eluted with a gradient of 5-20\% of solvent B for $5 \mathrm{~min}, 20-40 \%$ of solvent B for $30 \mathrm{~min}$, $95 \%$ of solvent B in $5 \mathrm{~min}, 95-5 \%$ solvent B in $1 \mathrm{~min}$, and 5\% of solvent B for $18 \mathrm{~min}$; Solvent A: 100\% water / $0.1 \%$ formic acid, Solvent B: $100 \%$ acetonitrile $10.1 \%$ formic acid. The flow rate was $300 \mathrm{~nL} / \mathrm{min}$ and the effluent was introduced into the QSTAR Elite ESI-QqTOF mass spectrometer (Applied Biosystems, Foster City, CA) via an uncoated $15 \mu \mathrm{m}$ i.d. PicoTip Emitter (New Objective Inc., Woburn, MA). The spray voltage was $2300 \mathrm{~V}$. The mass spectrometer was set to do the Information Dependent Acquisition (IDA) which automatically acquire TOF MS (survey) spectra at the $\mathrm{m} / \mathrm{z}$ range $350-2500 \mathrm{Da}$ and MS/MS (dependent) spectra on the five most intense doubly or triply charged peptides. The precursor ions selected previously were excluded for $60 \mathrm{~s}$ and an inclusion list of biomarker candidates was used.

\section{Peptide identification and sequencing}

The database searches for peptide identification were performed using Mascot and PepArML. For Mascot analysis, the raw MS/MS spectra were processed using Mascot Distiller and searched against the NCBInr human database. No enzyme was considered in these searches. MS peptide tolerance was $100 \mathrm{ppm}$ and MS/MS tolerance was 0.3 Da. Peptides identified with E-values $<0.01$ are shown in Table 1. For peptide identification using PepArML, MS/MS spectra were reformatted as mzXML format using PyMsXML (HU http://www.bioinformatics.org/groups/?group_id=701). The resulting files were searched against the IPI-Human protein sequence database using the PepArML metasearch engine, incorporating search engines Mascot, $\mathrm{X}$ !Tandem, OMSSA, and Myrimatch. Search engines were configured for non-specific peptides, precursor tolerance 2.0 Da, fragment tolerance $0.4 \mathrm{Da}$, fixed carbamidomethyl Cys modification, and variable Met oxidation, pyro-Glu on N-terminal Glu and Gln, and pyrocarbamidomethyl on $\mathrm{N}$-terminal Cys modifications. In addition to searches against the target IPI-Human protein sequence database, searches against ten independently shuffled decoy sequence databases were carried out using otherwise identical search parameters. The PepArML result combiner was used to unify the target and decoy results from the four search engines. The results of one decoy search was used for internal PepArML calibration, while the results of the other nine decoy searches were used to estimate the false discovery rate (FDR) of PepArML's peptide identifications. The unsupervised PepArML machine-learning algorithm used each search engine's E-value, the precursor mass delta, and the number of agreeing search engines to distinguish correct from incorrect peptide identifications. PepArML peptide identifications with estimated FDR of $10 \%$ or better were considered in the analysis.

\section{Results}

\subsection{Identification of candidate biomarkers for the detection of hepatocellular carcinoma}

We have previously reported mass spectrometric quantification that identified differentially abundant peptides associated with HCC; these studies compared $73 \mathrm{HCC}$ cases, 72 age- and gender- matched cancer-free 
controls, and 52 controls with chronic liver disease [1921]. The studies focused on native (non-tryptic) peptides in the low mass fraction of serum enriched by denaturing ultrafiltration. In those studies, the sequencing by direct MALDI-TOF/TOF fragmentation was successful for only a limited number of peptides. Here we report LC-MS/MS identification of the differentially abundant peptides that separated HCC patients from the healthy and chronic liver disease controls (Table 1) [19-21].

To identify the marker candidates, we enriched native peptides/low mass proteins by denaturing ultafiltration in $8 \mathrm{M}$ guanidine $\mathrm{HCl}$ followed by reverse phase fractionation on a monolithic HPLC column. We have analyzed samples from cancer patients, chronic liver disease patients, and disease free controls and found the fractionation reproducible with candidate peptides eluting in the same fractions across the samples (data not shown). Each fraction was first analyzed by MALDITOF/TOF which provided a link to the MALDI-TOF quantitative analyses. Fragmentation of the enriched peptides provided sufficiently rich $\mathrm{b}$ and $\mathrm{y}$ ion series to allow high confidence identification of complement fragments and other non-tryptic peptide candidates (FDR $<0.05$ ). We used nanoLC-MS/MS to confirm identification of the peptides and to identify additional peptides that did not provide sufficient fragment information using the MALDI ionization.

The peptide at $\mathrm{m} / \mathrm{z} 1865$, consistently higher in healthy and chronic liver disease controls in our previous studies [19-21], has been identified previously as the fragment of complement $\mathrm{C} 3 \mathrm{f}$ with the sequence SSKITHRIHWESASLL. In this study, we identified consistently five additional peptide fragments of $\mathrm{C} 3 \mathrm{f}$ with the same $\mathrm{C}$ terminus. Three of these have also higher observed intensities in our previous comparison of chronic liver disease controls compared to HCC. Two peptides $(\mathrm{m} / \mathrm{z} 1739,2377)$, elevated in sera of HCC patients, were identified as fragments of complement C4a (Table 2). We list all the identified peptides from the complement proteins, including the candidate markers, in Table 2. The ladder-like pattern (sequential one amino acid shortening at the $\mathrm{N}$ - and/or C-termini) indicates that exoproteases are likely involved in the processing of the peptides, as described previously [23].

The candidate marker at $\mathrm{m} / \mathrm{z} 2,530$, which is increased in HCC patients, was identified as a 24-amino acid peptide from coagulation factor XIII A with an arginine at the $\mathrm{C}$ terminus (Table 1 ). The peptide identity was confirmed by complementary fragmentation of the peptide in several different patient samples which further increases confidence of the identification. The complementary fragments from spectra of the same peptide obtained from multiple samples were observed for a number of the peptides in our study (data not shown). Two additional sequenced peptides were associated with HCC (Table 1). A peptide at $\mathrm{m} / \mathrm{z} 2,303$ was identified as a zyxin peptide using LC-MALDIMS/MS and a peptide at $\mathrm{m} / \mathrm{z}$ 1,379 was sequenced as a fibrinogen $\alpha$ peptide using nanoESI-MS/MS.

One of the peaks at $\mathrm{m} / \mathrm{z} 933$, increased in sera of HCC patients [19], is not a peptide. The MS/MS spectra of this compound showed a dominant fragment at $\mathrm{m} / \mathrm{z} 759$ which corresponds to the loss of glucuronide (Fig. 1). Analysis of the smaller fragments at $\mathrm{m} / \mathrm{z} 741$, 583,473 and 298 is consistent with the structure of biliverdin diglucuronide which confirms the unexpected finding of a metabolite in our study of peptidic marker candidates.

\section{Global peptide identification (from LMW human blood fraction using LC-MS/MS)}

Human serum is a complex mixture containing more than $10^{4}$ proteins with wide range of physico-chemical properties and an immense dynamic range $\left(\sim 10^{8}\right)$ [24]. To improve our sequencing effort, we employed denaturing ultrafiltration to enrich the LMW fraction of serum or plasma; native peptides were further separated by reverse phase chromatography. The sequencing in the serum samples identified a total of 245 native peptides deriving from 48 proteins (Table 3 ). We observed ladder-like truncations at either $\mathrm{N}$ - or C-termini of the identified sequences as reported by Villanueva and colleagues [14,24]. About $20 \%$ of the sequences belong to fibrinogen alpha, the dominant component of the LMW fraction of serum. We analyzed samples of HCC patients with high ion intensity of those candidates in order to identify some of the peptides with low intensity in controls. We found that 27 peptides that were identifiable only in patient sera including peptides with $\mathrm{m} / \mathrm{z} 2,530$ and 2,303 (Table 1). In addition to serum, we also examined plasma and found that at least twenty peptides deriving from fibrinogen $\alpha$, interalpha-trypsin inhibitor heavy chain $\mathrm{H} 4$, thymosin beta4, zyxin, alpha-2-HS-glycoprotein precursor, fibrinogen beta, complement $\mathrm{C} 4$ and serum albumin were also present in plasma. 
Table 2

Peptide ladders derived from complement. Bolded complement $\mathrm{C} 3$ peptides are higher in controls; bolded complement $\mathrm{C} 4$ peptides are higher in $\mathrm{HCC}$; regular font peptides did not change [19,21]

\begin{tabular}{|c|c|c|}
\hline Protein name & Observed mass & Sequence \\
\hline Complement C3 & $\begin{array}{r}2021.10 \\
1934.07 \\
\mathbf{1 8 6 4 . 9 9} \\
\mathbf{1 7 7 7 . 9 7} \\
\mathbf{1 6 9 0 . 9 4} \\
\mathbf{1 5 6 2 . 8 4} \\
1211.65 \\
942.47 \\
1855.85 \\
1768.82 \\
1471.74 \\
1206.61 \\
1816.89 \\
2089.05\end{array}$ & $\begin{array}{l}\text { SSKITHRIHWESASLLR } \\
\text { SKITHRIHWESASLLR } \\
\text { SSKITHRIHWESASLL } \\
\text { SKITHRIHWESASLL } \\
\text { KITHRIHWESASLL } \\
\text { ITHRIHWESASLL } \\
\text { RIHWESASLL } \\
\text { HWESASLL } \\
\text { SEETKENEGFTVTAEGK } \\
\text { EETKENEGFTVTAEGK } \\
\text { AAVYHHFISDGVR } \\
\text { SVQLTEKRMD } \\
\text { SNLDEDIIAEENIVSR } \\
\text { GYTQQLAFRQPSSAFAAFV }\end{array}$ \\
\hline Complement C4A & $\begin{array}{l}1626.84 \\
\mathbf{1 7 3 9 . 9 2} \\
1896.028 \\
1781.99 \\
1625.88 \\
1512.80 \\
1449.81 \\
1293.70 \\
1052.56 \\
\mathbf{2 3 7 8 . 1 9} \\
2108.07 \\
2225.12\end{array}$ & $\begin{array}{l}\text { NGFKSHALQLNNRQ } \\
\text { NGFKSHALQLNNRQI } \\
\text { NGFKSHALQLNNRQIR } \\
\text { GFKSHALQLNNRQIR } \\
\text { GFKSHALQLNNRQI } \\
\text { GFKSHALQLNNRQ } \\
\text { SHALQLNNRQIR } \\
\text { SHALQLNNRQI } \\
\text { SHALQLNNR } \\
\text { DDPDAPLQPVTPLQLFEGRRN } \\
\text { DDPDAPLQPVTPLQLFEGR } \\
\text { ALEILQEEDLIDEDDIPVR }\end{array}$ \\
\hline
\end{tabular}

\section{Discussion}

Incidence of hepatocellular carcinoma (HCC) in the US increases and has been associated with hepatitis $\mathrm{C}(\mathrm{HCV})$ viral infection. Very high rates of HCC are observed in Egypt where HCV presents a serious health problem $[25,26]$. Our studies of native peptides in serum samples from the Egyptian population identified several peptides associated with the development of HCC [19-21] that could potentially serve as a serologic marker.

We have reported previously the identification of two peptides $\mathrm{m} / \mathrm{z} 1864$ and 1739 [19]. In this continuation of our previous studies, we describe identification of seven new peptides and a metabolite associated with HCC. These peptides derive from complement C3 (m/z, 1777, 1690 and 1562), complement C4 (m/z 2377), coagulation factor XIII (m/z 2530), zyxin (m/z 2303), and fibrinogen $\alpha(\mathrm{m} / \mathrm{z} 1379)$; the spectra of a metabolite associated with $\mathrm{HCC}$ are consistent with biliverdin diglucuronide (m/z 933) (Fig. 1). These proteins are produced by the liver and it is plausible that differential enzymatic processing and distribution associated with liver disease produces peptides diagnostic of the disease progression. We did observe an association of these peptides with HCC in a study of approximately 200 patients progressing from HCV infection to HCC [1921]. A combination of the peptides was able to identify HCC with better than $90 \%$ prediction accuracy [22,27]. While differential processing of these relatively abundant serum proteins is likely to reflect the progression of liver disease, the specificity for the detection of HCC will have to be carefully evaluated [28]. Indeed, some of the peptides were previously associated with other cancers [29-32] and may be progressively changing with the development of pre-malignant liver disease. In our study, we did observe a strong association of HCC cases and population controls with fibrinopeptide (m/z 1379), coagulation factor XIII A (m/z 2530), and biliverdin diglucuronide $(\mathrm{m} / \mathrm{z} 933)$ but these molecules did not separate well HCC from cirrhotic controls. The complement $\mathrm{C} 3$ and $\mathrm{C} 4$ peptides and a peptide derived from zyxin were best at separating HCC patients from cirrhotic controls. The prediction accuracy for the detection of HCC has to be further evaluated by independent methods in samples from an appropriate population before any claims of biomarker potential can be made. 


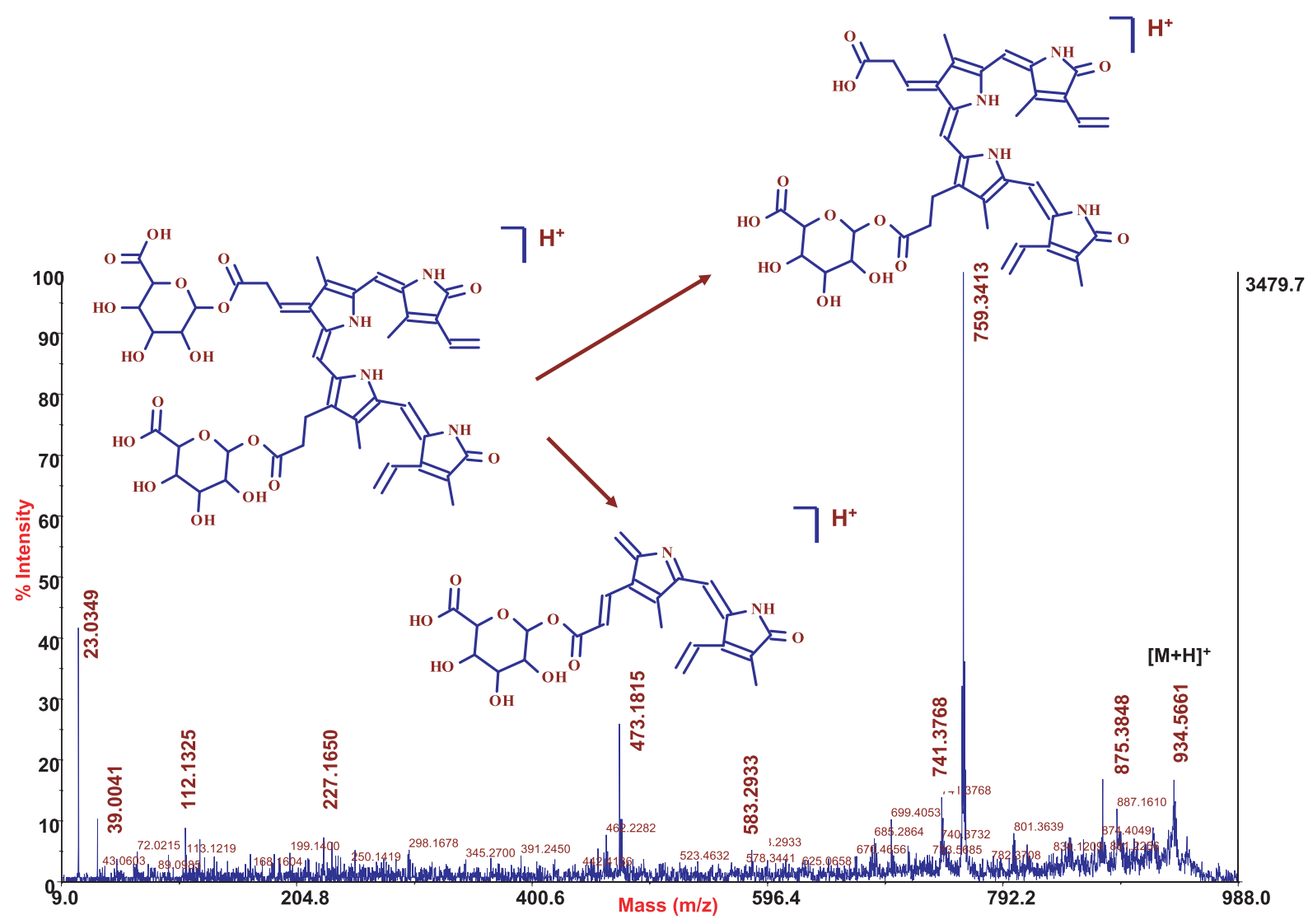

Fig. 1. Tandem mass spectrum of the analyte observed at m/z 934.32 is consistent with the fragmentation of biliverdin diglucoronide.

Three peptides from complement C3f $(\mathrm{m} / \mathrm{z} 1864$, 1777,1690 and 1562) decrease progressively from disease free controls to chronic liver disease and HCC [1921]. In contrast, two peptides derived from complement $\mathrm{C} 4$ are more abundant in the sera of HCC patients. The changes in complement $\mathrm{C} 3$ have been associated with a number of malignancies including T-cell leukemia [30], nasopharyngeal cancer [31], breast cancer [14], and chronic B-cell lymphoid malignancy [33]. Differential expression of complement $\mathrm{C} 4$ peptides was also observed in several case-control studies [14,34]. We expected that our denaturing ultrafiltration procedure will enrich the samples compared to the published studies of whole serum [14,34]. We also expected that the disease of the liver, an organ producing majority of the proteins identified in serum, will affect peptide composition more than other cancers. However, we observe in our study a similar set of peptides.

Complement is a mediator of inflammation and contributes to the regulation of immune responses. The complement system contains more than 30 glycoproteins which regulate liver regeneration $[35,36]$, immune responses [37,38] and other important processes in many as yet incompletely characterized ways [39]. The observed complement peptides are postulated to derive from endoproteolytic cleavage of $\mathrm{C} 3$ and $\mathrm{C} 4$ proteins followed by exopeptidase trimming [14,34]. Three biochemical pathways are known to activate the complement system: the classical complement pathway, the alternative complement pathway, and the mannosebinding lectin pathway. C3 plays a central role in the activation of the complement system of all three pathways [40]. The complement peptides have different abundance in various diseases $[14,19,34,40,41]$ which indicates that they serve important functions but may decrease their applicability as specific markers. It is interesting to note, however, that a tumor specific exoprotease processing and activity screening of complement peptides was recently proposed for cancer-specific detection [24].

The peptide $\mathrm{m} / \mathrm{z} 2,303$, increased in the serum of HCC patients, derives from zyxin. Upregulation of zyxin in HCC tumors had been previously observed by quantitative reverse transcription-polymerase chain re- 
Table 3

Serum proteins whose native peptides were identified in this study. The peptide\# indicates numbers of native peptides observed for each of the proteins

\begin{tabular}{|c|c|c|}
\hline Protein name & Access \# & Peptide \# \\
\hline Fibrinogen alpha chain & P02671 & 47 \\
\hline Inter-alpha-trypsin inhibitor heavy chain $\mathrm{H} 4$ & Q14624 & 25 \\
\hline Complement $\mathrm{C} 3$ & P01024 & 14 \\
\hline Apolipoprotein A-I & P02647 & 14 \\
\hline Kininogen-1 & P01042 & 13 \\
\hline Zyxin & Q15942 & 12 \\
\hline Complement component 4A & P0C0L4 & 12 \\
\hline Fibrinogen beta chain & P02675 & 12 \\
\hline Apolipoprotein A-IV & P06727 & 12 \\
\hline Prothrombin & P00734 & 9 \\
\hline Alpha-2-macroglobulin & P01023 & 6 \\
\hline Serotransferrin & P02787 & 6 \\
\hline Plexin domain-containing protein 2 & Q6UX71 & 4 \\
\hline Transthyretin & P02766 & 4 \\
\hline Alpha-2-HS-glycoprotein precursor & P02765 & 4 \\
\hline Thymosin beta- 4 & P62328 & 3 \\
\hline Coagulation factor XIII A chain precursor & P00488 & 3 \\
\hline Haptoglobin & P00738 & 3 \\
\hline Alpha-1-antitrypsin & HP01009 & 3 \\
\hline Clusterin & P10909 & 3 \\
\hline Serglycin & P10124 & 2 \\
\hline Serum albumin & P02768 & 2 \\
\hline Apolipoprotein C-III & P02656 & 2 \\
\hline Apolipoprotein E & P02649 & 2 \\
\hline Hemopexin & P02790 & 2 \\
\hline Serum amyloid-A4 protein & P35542 & 2 \\
\hline Complement $\mathrm{C} 1 \mathrm{r}$ & P00736 & 2 \\
\hline Vitronectin & P04004 & 2 \\
\hline Collagen alpha-3(V) chain & $\mathrm{P} 25940$ & 1 \\
\hline Collagen alpha-5(IV) chain & P29400 & 1 \\
\hline Glycogen debranching enzyme & P35573 & 1 \\
\hline Synapsin-1 & P17600 & 1 \\
\hline Coagulation factor $\mathrm{V}$ & P12259 & 1 \\
\hline Transmembrane channel-like protein 6 & Q7Z403 & 1 \\
\hline Multimerin-1 & Q13201 & 1 \\
\hline Vasodilator-stimulated phosphoprotein & P50552 & 1 \\
\hline Actin, cytoplasmic 2 & P63261 & 1 \\
\hline Dermcidin & P81605 & 1 \\
\hline Putative serum amyloid A-3 protein & $\mathrm{P} 22614$ & 1 \\
\hline Apolipoprotein A-II & P02652 & 1 \\
\hline LIM and SH3 domain protein 1 & Q14847 & 1 \\
\hline Corticotropin-lipotropin & P01189 & 1 \\
\hline ADP-ribosylation factor-like protein 6 -interacting protein 4 & Q66PJ3 & 1 \\
\hline Antithrombin & Q8IZZ8 & 1 \\
\hline Alpha-2-antiplasmin & P08697 & 1 \\
\hline Chondroitin sulfate proteoglycan 4 & Q6UVK1 & 1 \\
\hline Gelsolin & P06396 & 1 \\
\hline Apolipoprotein L1 & O14791 & 1 \\
\hline
\end{tabular}

action [42]. Zyxin is a focal-adhesion-associated phosphoprotein with an apparent molecular weight of 82$84 \mathrm{kDa}$. It has been reported that zyxin expression plays a role in the motility of HCC cells, cell migration, and intravasation through its action on actin cytoskeleton [43]. Zyxin promoted cell dissemination as a part of the integrin-signaling pathway [43].

The fibrinogen and coagulation factor XIII A are components of the blood coagulation cascade. The coagulation process involves thrombin-dependent cleavage of fibrinogen with the release of fibrinopeptide $\alpha$. Fibrinogen is the most abundance source of peptides in our study and was also found to be associate with the presence of cancer in other studies $[31,43,44]$. We identified ladders of $\mathrm{N}$ - or $\mathrm{C}$-terminal truncations of serum peptides as reported previously by several groups [14, 
39,35]. The most likely explanation for the presence of these peptides is the presence of different exoprotease activities superimposed on an aberrant clotting process $[14,24,45]$. Our study was conducted in serum; however, we still observed the ladder of peptides derived from fibrinogen $\alpha$ when we analyzed EDTA plasma from disease free controls. Cancer is known to be associated with disorders of hemostasis and it is still unclear how much fragmentation occurs in vivo and what are the functional implications [46-50].

The spectrum in Fig. 1 is consistent with the fragmentation of biliverdin diglucuronide. Biliverdin is a product of heme breakdown. Biliverdin reductase reduces biliverdin to water insoluble bilirubin which is conjugated with glucuronic acid, mainly in the liver, by the enzyme UDP-glucuronyltransferase and excreted. Several authors pointed out that bilirubin is likely to play important physiological functions because biliverdin is water soluble and could be directly excreted. It was already shown that bilirubin has antioxidant [51] and immunomodulatory [52] functions. Bilirubin diglucuronide is a sign of liver injury; biliverdin diglucuronide is possibly an oxidation product of bilirubin diglucuronide reflective of liver injury [53]. We observed an increase in biliverdin diglucuronide in HCC compared to population controls [19-21] but the difference was not detected compared to cirrhosis controls [19-21].

In conclusion, we identified peptides and a metabolite associated with the presence of HCC by mass spectrometric sequencing. The peptides of complement $\mathrm{C} 3$, complement $\mathrm{C} 4$ and zyxin likely derive from a complex exopeptidase activity superimposed on differentially abundant peptides related to HCC. These peptides could potentially serve as markers of HCC; however, association of similar peptides with other diseases and cancers dictates a very cautious approach.

\section{Acknowledgment}

We want to thank Drs Chris Loffredo, Mohamed Abdel-Hamid, Gamal Ezmat, and Sameera Ezzat for providing access to the patient samples used in our studies. We want to thank Dr. Ressom for assistance in the quantification of our previous mass spectrometric measurements. This work was supported in part by an Associate Membership from NCI's Early Detection Research Network, R01 CA115625 awarded to RG, R01 CA 126189 awarded to NE, and a fellowship from Cancer Prevention Foundation awarded to YA. The authors have declared no conflict of interest.

\section{References}

[1] F.X. Bosch, J. Ribes, M. Diaz and R. Cleries, Primary liver cancer: worldwide incidence and trends, Gastroenterology 127 (2004), S5-S16.

[2] H. Tammen, I. Schulte, R. Hess, C. Menzel, M. Kellmann and P. Schulz-Knappe, Prerequisites for peptidomic analysis of blood samples: I. Evaluation of blood specimen qualities and determination of technical performance characteristics, Comb Chem High Throughput Screen 8 (2005), 725-733.

[3] H.B. el Serag, Hepatocellular carcinoma: recent trends in the United States, Gastroenterology 127 (2004), S27-S34.

[4] H.B. el Serag and A.C. Mason, Rising incidence of hepatocellular carcinoma in the United States, $N$ Engl J Med 340 (1999), 745-750.

[5] J.B. Wong, G.M. McQuillan, J.G. McHutchison and T. Poynard, Estimating future hepatitis $\mathrm{C}$ morbidity, mortality, and costs in the United States, Am J Public Health 90 (2000), $1562-1569$.

[6] T.J. Liang and T. Heller, Pathogenesis of hepatitis C-associated hepatocellular carcinoma, Gastroenterology 127 (2004), S62S71.

[7] T.J. Liang, L.J. Jeffers, K.R. Reddy, M. De Medina, I.T. Parker, H. Cheinquer, V. Idrovo, A. Rabassa and E.R. Schiff, Viral pathogenesis of hepatocellular carcinoma in the United States, Hepatology 18 (1993), 1326-1333.

[8] J.C. Sheu, J.L. Sung, D.S. Chen, M.Y. Lai, T.H. Wang, J.Y. Yu, P.M. Yang, C.N. Chuang, P.C. Yang and C.S. Lee, Early detection of hepatocellular carcinoma by real-time ultrasonography. A prospective study, Cancer 56 (1985), 660-666.

[9] B. Daniele, A. Bencivenga, A.S. Megna and V. Tinessa, Alphafetoprotein and ultrasonography screening for hepatocellular carcinoma, Gastroenterology 127 (2004), S108-S112.

[10] M.A. Comunale, M. Wang, J. Hafner, J. Krakover, L. Rodemich, B. Kopenhaver, R.E. Long, O. Junaidi, A.M. Bisceglie, T.M. Block and A.S. Mehta, Identification and development of fucosylated glycoproteins as biomarkers of primary hepatocellular carcinoma, J Proteome Res 8 (2009), 595-602.

[11] V. Paradis, F. Degos, D. Dargere, N. Pham, J. Belghiti, C. Degott, J.L. Janeau, A. Bezeaud, D. Delforge, M. Cubizolles, I. Laurendeau and P. Bedossa, Identification of a new marker of hepatocellular carcinoma by serum protein profiling of patients with chronic liver diseases, Hepatology 41 (2005), 40-47.

[12] M.J. Lee, G.R. Yu, S.H. Park, B.H. Cho, J.S. Ahn, H.J. Park, E.Y. Song and D.G. Kim, Identification of cystatin B as a potential serum marker in hepatocellular carcinoma, Clin Cancer Res 14 (2008), 1080-1089.

[13] M. Sakamoto, Early HCC: diagnosis and molecular markers, J Gastroenterol 44 Suppl 19 (2009), 108-111.

[14] J. Villanueva, D.R. Shaffer, J. Philip, C.A. Chaparro, H. Erdjument-Bromage, A.B. Olshen, M. Fleisher, H. Lilja, E. Brogi, J. Boyd, M. Sanchez-Carbayo, E.C. Holland, C. Cordon-Cardo, H.I. Scher and P. Tempst, Differential exoprotease activities confer tumor-specific serum peptidome patterns, J Clin Invest 116 (2006), 271-284.

[15] M.A. Feitelson, J. Pan and Z. Lian, Early molecular and genetic determinants of primary liver malignancy, Surg Clin North Am 84 (2004), 339-354.

[16] Z. Sun and P. Yang, Role of imbalance between neutrophil elastase and alpha 1-antitrypsin in cancer development and progression, Lancet Oncol 5 (2004), 182-190. 
[17] X.D. Zhou, Recurrence and metastasis of hepatocellular carcinoma: progress and prospects, Hepatobiliary Pancreat Dis Int 1 (2002), 35-41.

[18] F.R. Rickles, M. Levine and R.L. Edwards, Hemostatic alterations in cancer patients, Cancer Metastasis Rev 11 (1992), 237-248.

[19] R. Goldman, H.W. Ressom, M. Abdel-Hamid, L. Goldman, A. Wang, R.S. Varghese, Y. An, C.A. Loffredo, S.K. Drake, S.A. Eissa, I. Gouda, S. Ezzat and F.S. Moiseiwitsch, Candidate markers for the detection of hepatocellular carcinoma in lowmolecular weight fraction of serum, Carcinogenesis $\mathbf{2 8}$ (2007), 2149-2153.

[20] E. Orvisky, S.K. Drake, B.M. Martin, M. Abdel-Hamid, H.W. Ressom, R.S. Varghese, Y. An, D. Saha, G.L. Hortin, C.A. Loffredo and R.Goldman, Enrichment of low molecular weight fraction of serum for mass spectrometric analysis of peptides associated with hepatocellular carcinoma, Proteomics 6 (2006), 2895-2902.

[21] H.W. Ressom, R.S. Varghese, L. Goldman, Y. An, C.A. Loffredo, M. Abdel-Hamid, Z. Kyselova, Y. Mechref, M. Novotny, S.K. Drake and R. Goldman, Analysis of MALDI-TOF mass spectrometry data for discovery of peptide and glycan biomarkers of hepatocellular carcinoma, J Proteome Res 7 (2008), 603-610.

[22] Y. An, H.W. Ressom and R. Goldman, Enrichment of Serum Peptides and Analysis by MALDI-TOF Mass Spectrometry in The Protein Protocols Handbook, 3rd edition, J. Walker editor, Humana Press (2009), 1167-1174.

[23] J. Villanueva, A. Nazarian, K. Lawlor, S.S. Yi, R.J. Robbins and P. Tempst, A sequence-specific exopeptidase activity test (SSEAT) for functional biomarker discovery, Mol Cell Proteomics 7 (2008), 509-518

[24] J.N. Adkins, S.M. Varnum, K.J. Auberry, R.J. Moore, N.H. Angell, R.D. Smith, D.L. Springer and J.G. Pounds, Toward a human blood serum proteome: analysis by multidimensional separation coupled with mass spectrometry, Mol Cell Proteomics 1 (2002), 947-955.

[25] S. Ezzat, M. Abdel-Hamid, S.A. Eissa, N. Mokhtar, N.A. Labib, L. El Ghorory, N.N. Mikhail, A. Abdel-Hamid, T. Hifnawy, G.T. Strickland and C.A. Loffredo, Associations of pesticides, HCV, HBV, and hepatocellular carcinoma in Egypt, Int J Hyg Environ Health 208 (2005), 329-339.

[26] M.K. Mohamed, Viral Hepatitis C Infection among Egyptians; The Magnitude of the Problem, Epidemiological and Laboratory Approach, Journal of Egyptian Public Health Association 71 (1996), 79-111.

[27] H.W. Ressom, R.S. Varghese, S.K. Drake, G.L. Hortin, M. Abdel-Hamid, C.A. Loffredo and R. Goldman, Peak selection from MALDI-TOF mass spectra using ant colony optimization, Bioinformatics 23 (2007), 619-626.

[28] E.P. Diamandis, Peptidomics for cancer diagnosis: present and future, J Proteome Res 5 (2006), 2079-2082.

[29] Y. Ishida, K. Yamashita, H. Sasaki, I. Takajou, Y. Kubuki, K. Morishita, H. Tsubouchi and A. Okayama, Activation of complement system in adult T-cell leukemia (ATL) occurs mainly through lectin pathway: a serum proteomic approach using mass spectrometry, Cancer Lett 271 (2008), 167-177.

[30] J.T. Chang, L.C. Chen, S.Y. Wei, Y.J. Chen, H.M. Wang, C.T. Liao, I.H. Chen and A.J. Cheng, Increase diagnostic efficacy by combined use of fingerprint markers in mass spectrometry plasma peptidomes from nasopharyngeal cancer patients for example, Clin Biochem 39 (2006), 1144-1151.

[31] M.P. Ebert, D. Niemeyer, S.O. Deininger, T. Wex, C. Knippig, J. Hoffmann, J. Sauer, W. Albrecht, P. Malfertheiner and
C. Rocken, Identification and confirmation of increased fibrinopeptide a serum protein levels in gastric cancer sera by magnet bead assisted MALDI-TOF mass spectrometry, $J$ Proteome Res 5 (2006), 2152-2158.

[32] L.F. Steel, D. Shumpert, M. Trotter, S.H. Seeholzer, A.A. Evans, W.T. London, R. Dwek and T.M. Block, A strategy for the comparative analysis of serum proteomes for the discovery of biomarkers for hepatocellular carcinoma, Proteomics 3 (2003), 601-6.

[33] L. Miguet, R. Bogumil, P. Decloquement, R. Herbrecht, N. Potier, L. Mauvieux and A. Van Dorsselaer, Discovery and identification of potential biomarkers in a prospective study of chronic lymphoid malignancies using SELDI-TOF-MS, $J$ Proteome Res 5 (2006), 2258-2269.

[34] J.M. Koomen, D. Li, L.C. Xiao, T.C. Liu, K.R. Coombes, J. Abbruzzese and R. Kobayashi, Direct tandem mass spectrometry reveals limitations in protein profiling experiments for plasma biomarker discovery, J Proteome Res 4 (2005), 972-981.

[35] C.W. Strey, M. Markiewski, D. Mastellos, R. Tudoran, L.A. Spruce, L.E. Greenbaum and J.D. Lambris, The proinflammatory mediators $\mathrm{C} 3 \mathrm{a}$ and $\mathrm{C} 5 \mathrm{a}$ are essential for liver regeneration, J Exp Med 198 (2003), 913-923.

[36] M.M. Markiewski, D. Mastellos, R. Tudoran, R.A. DeAngelis, C.W. Strey, S. Franchini, R.A. Wetsel, A. Erdei and J.D. Lambris, $\mathrm{C} 3 \mathrm{a}$ and $\mathrm{C} 3 \mathrm{~b}$ activation products of the third component of complement (C3) are critical for normal liver recovery after toxic injury, J Immunol 173 (2004), 747-754.

[37] P. Gasque, Complement: a unique innate immune sensor for danger signals, Mol Immunol 41 (2004), 1089-1098.

[38] C. Kemper and J.P. Atkinson, T-cell regulation: with complements from innate immunity, Nat Rev Immunol 7 (2007), 9-18.

[39] A. Sahu and J.D. Lambris, Structure and biology of complement protein $\mathrm{C} 3$, a connecting link between innate and acquired immunity, Immunol Rev 180 (2001), 35-48.

[40] V.S. Ganu, H.J. Muller-Eberhard and T.E. Hugli, Factor C3f is a spasmogenic fragment released from $\mathrm{C} 3$ b by factors I and $\mathrm{H}$ : the heptadeca-peptide C3f was synthesized and characterized, Mol Immunol 26 (1989), 939-948.

[41] J. Marshall, P. Kupchak, W. Zhu, J. Yantha, T. Vrees, S. Furesz, K. Jacks, C. Smith, I. Kireeva, R. Zhang, M. Takahashi, E. Stanton and G. Jackowski, Processing of serum proteins underlies the mass spectral fingerprinting of myocardial infarction, J Proteome Res 2 (2003), 361-372.

[42] S.M. Sy, P.B. Lai, E. Pang, N.L. Wong, K.F. To, P.J. Johnson and N. Wong, Novel identification of zyxin upregulations in the motile phenotype of hepatocellular carcinoma, Mod Pathol 19 (2006), 1108-1116

[43] H.R. Bergen, III, G. Vasmatzis, W.A. Cliby, K.L. Johnson, A.L. Oberg and D.C. Muddiman, Discovery of ovarian cancer biomarkers in serum using NanoLC electrospray ionization TOF and FT-ICR mass spectrometry, Dis Markers 19 (2003), 239-249.

[44] D. Theodorescu, S. Wittke, M.M. Ross, M. Walden, M. Conaway, I. Just, H. Mischak and H.F. Frierson, Discovery and validation of new protein biomarkers for urothelial cancer: a prospective analysis, Lancet Oncol 7 (2006), 230-240.

[45] M.T. Davis and S.D. Patterson, Does the serum peptidome reveal hemostatic dysregulation? Ernst Schering Res Found Workshop (2007), 23-44.

[46] J. Rak, J.L. Yu, J. Luyendyk and N. Mackman, Oncogenes, trousseau syndrome, and cancer-related changes in the coagulome of mice and humans, Cancer Res 66 (2006), 10643- 
10646

[47] R. Kaufmann, S. Rahn, K. Pollrich, J. Hertel, Y. Dittmar, M. Hommann, P. Henklein, C. Biskup, M. Westermann, M.D. Hollenberg and U. Settmacher, Thrombin-mediated hepatocellular carcinoma cell migration: cooperative action via proteinase-activated receptors 1 and 4, J Cell Physiol 211 (2007), 699-707.

[48] G. Hjortoe, B.B. Sorensen, L.C. Petersen and L.V. Rao, Factor VIIa binding and internalization in hepatocytes, J Thromb Haemost 3 (2005), 2264-2273.

[49] P.C. Winter, The pathogenesis of venous thromboembolism in cancer: emerging links with tumour biology, Hematol Oncol 24 (2006), 126-133.

[50] G.J. Miller, K.A. Bauer, D.J. Howarth, J.A. Cooper, S.E. Humphries and R.D. Rosenberg, Increased incidence of neo- plasia of the digestive tract in men with persistent activation of the coagulant pathway, J Thromb Haemost 2 (2004), 21072114.

[51] D.E. Baranano, M. Rao, C.D. Ferris and S.H. Snyder, Biliverdin reductase: a major physiologic cytoprotectant, Proc Natl Acad Sci U S A 99 (2002), 16093-16098.

[52] Y. Liu, P. Li, J. Lu, W. Xiong, J. Oger, W. Tetzlaff and M. Cynader, Bilirubin possesses powerful immunomodulatory activity and suppresses experimental autoimmune encephalomyelitis, J Immunol 181 (2008), 1887-1897.

[53] M. Niittynen, J.T. Tuomisto, S. Auriola, R. Pohjanvirta, P. Syrjala, U. Simanainen, M. Viluksela and J. Tuomisto, 2,3,7,8tetrachlorodibenzo-p-dioxin (TCDD)-induced accumulation of biliverdin and hepatic peliosis in rats, Toxicol Scibf 71 (2003), 112-123. 


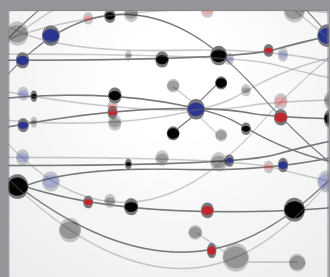

The Scientific World Journal
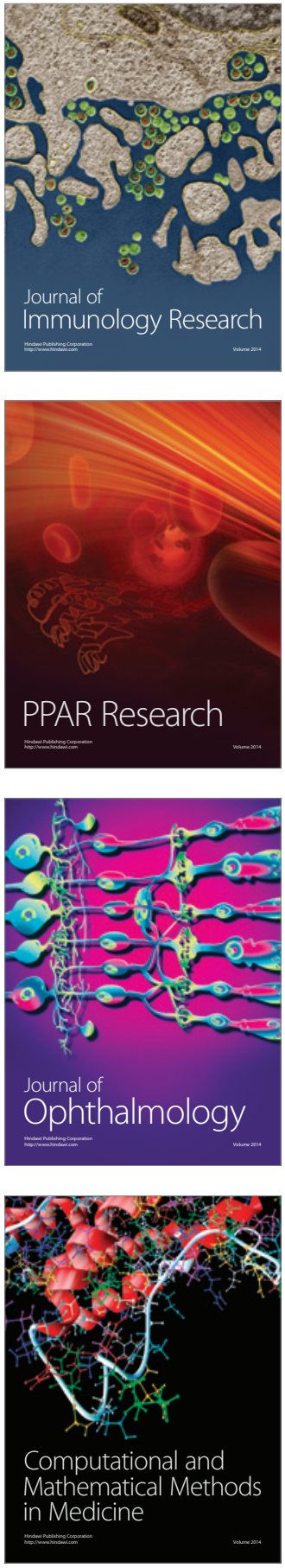

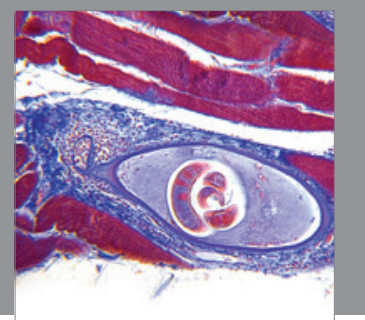

Gastroenterology

Research and Practice
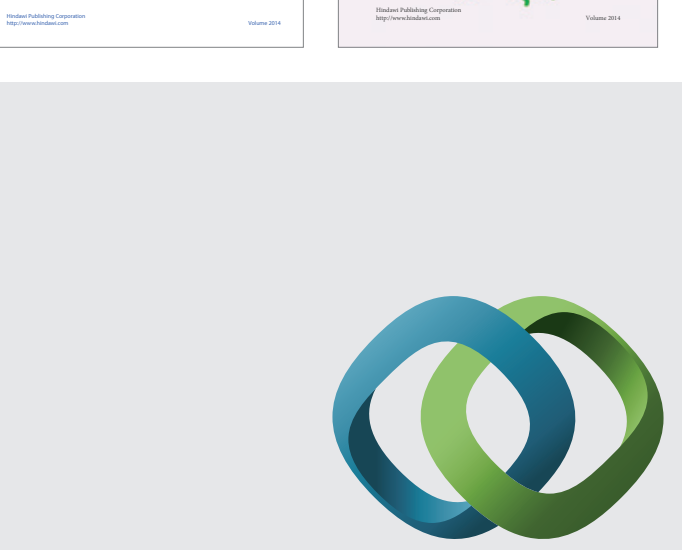

\section{Hindawi}

Submit your manuscripts at

http://www.hindawi.com
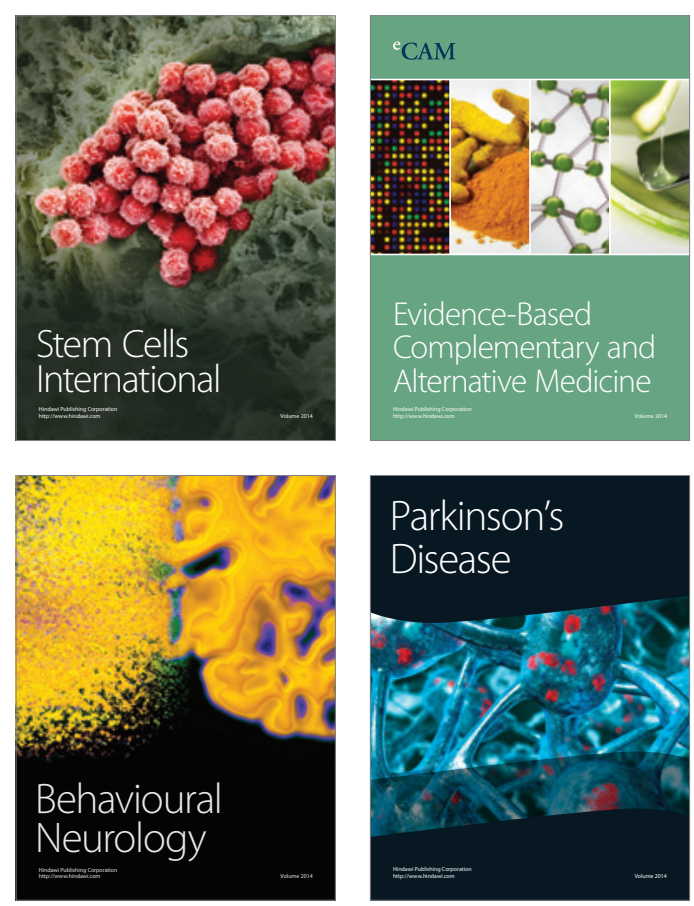

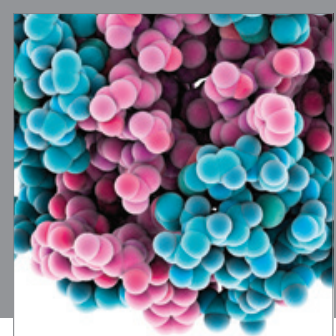

Journal of
Diabetes Research

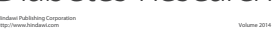

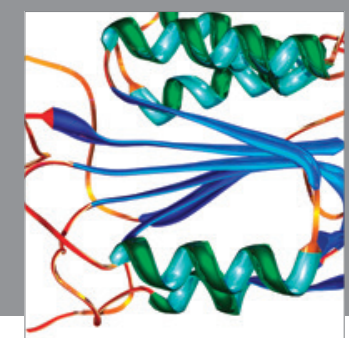

Disease Markers
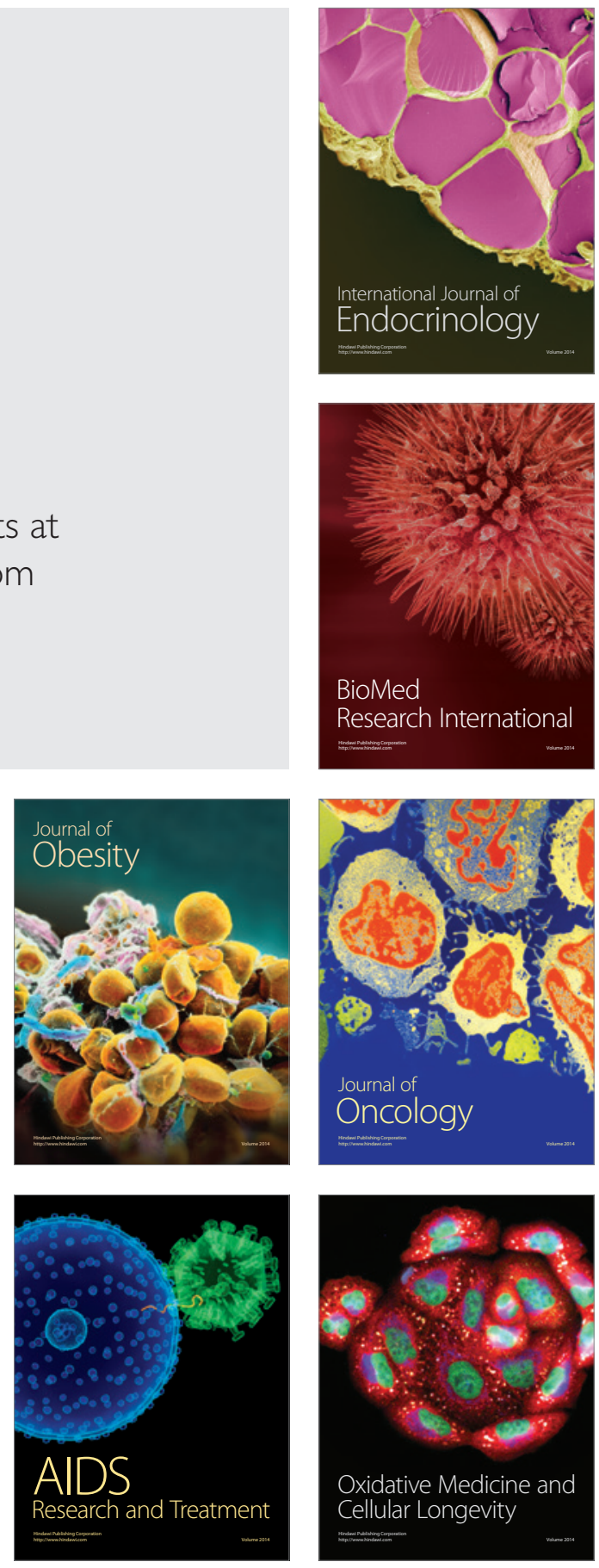